ORIGINAL ARTICLE

\title{
Hypernatraemia in South African hospitalized patients
}

\author{
Ali Abohajir', Megan A Rensburg², M Razeen Davids' \\ 'Division of Nephrology, Stellenbosch University and Tygerberg Hospital, Cape Town, South Africa; 'Division of Chemical Pathology, \\ National Health Laboratory Service, Stellenbosch University and Tygerberg Hospital, Cape Town, South Africa.
}

\section{ABSTRACT}

Background: Hypernatraemia is a common electrolyte problem in hospitalized patients and is associated with a high mortality rate. We determined the incidence, causes, management, and outcomes of hypernatraemia in adult hospitalized patients at a large South African tertiary hospital.

Methods: A retrospective study was conducted at Tygerberg Hospital in Cape Town, South Africa. Adult patients with hypernatraemia (at least one serum sodium concentration $\geq 150 \mathrm{mmol} / \mathrm{L}$ ) during a 3-month period in 2014 were identified from our laboratory database for inclusion.

Results: There were 204 patients with hypernatraemia, a prevalence of 1.5\%. Of these patients, I0I (49.5\%) were male, and the mean age was 53 years. There were 66 patients (32.4\%) who had hypernatraemia on admission, and 138 who developed it during the course of their stay in hospital. The overall in-hospital mortality was $38.7 \%$, with higher rates for older patients and those with more severe degrees of hypernatraemia. Contributory causes which were most commonly present included dehydration/hypovolaemia (45\%), followed by sepsis (39\%). Net sodium gain, rather than water deficit, was identified as the main mechanism in most of the patients who developed hypernatraemia in the intensive care units. We found little evidence of any diagnostic work-up and also found that the details of fluid therapy and intake-output charting were poorly documented.

Conclusions: There is a very high mortality rate in our hospitalized patients with hypernatraemia. The diagnostic work-up and therapy were often inadequate or poorly documented. The management of this important condition needs to be improved with the aid of standardized protocols.

Keywords: hypernatraemia; tonicity balance; South Africa.

\section{INTRODUCTION}

Hypernatraemia is defined as a rise in serum sodium concentration $\left(\left[\mathrm{Na}^{+}\right]\right)$to a value exceeding $145 \mathrm{mmol} / \mathrm{L}$ [I]. It is a hyperosmolar condition caused by a decrease in total body water relative to sodium content and is best thought of as a problem of water homeostasis, rather than a "sodium problem". The high osmolality is associated with shrinking in cell volume and the potential dangers for affected patients therefore relate to brain cell shrinkage [I]. Confusion, seizures or coma may result. Subcortical or subarachnoid haemorrhage, and venous thrombosis have been described in patients who died of severe hypernatraemia [2].

In healthy individuals, water loss seldom leads to hypernatraemia because the increase in osmolality stimulates renal water conservation and thirst, leading to increased water intake, which lowers the sodium concentration back towards the normal range. Thus, hypernatraemia primarily occurs in those patients who are unable to sense thirst or respond to thirst normally by gaining access to water [2,3].

The diagnostic work-up of a hypernatraemic patient usually includes the assessment of extracellular fluid (ECF) volume, and measurement of urine osmolality and electrolytes. Figure $\mathrm{I}$ is an example of a diagnostic algorithm. Such algorithms should form the basis of standard protocols for the diagnostic workup and treatment of affected patients. 


\section{HYPERNATRAEMIA}

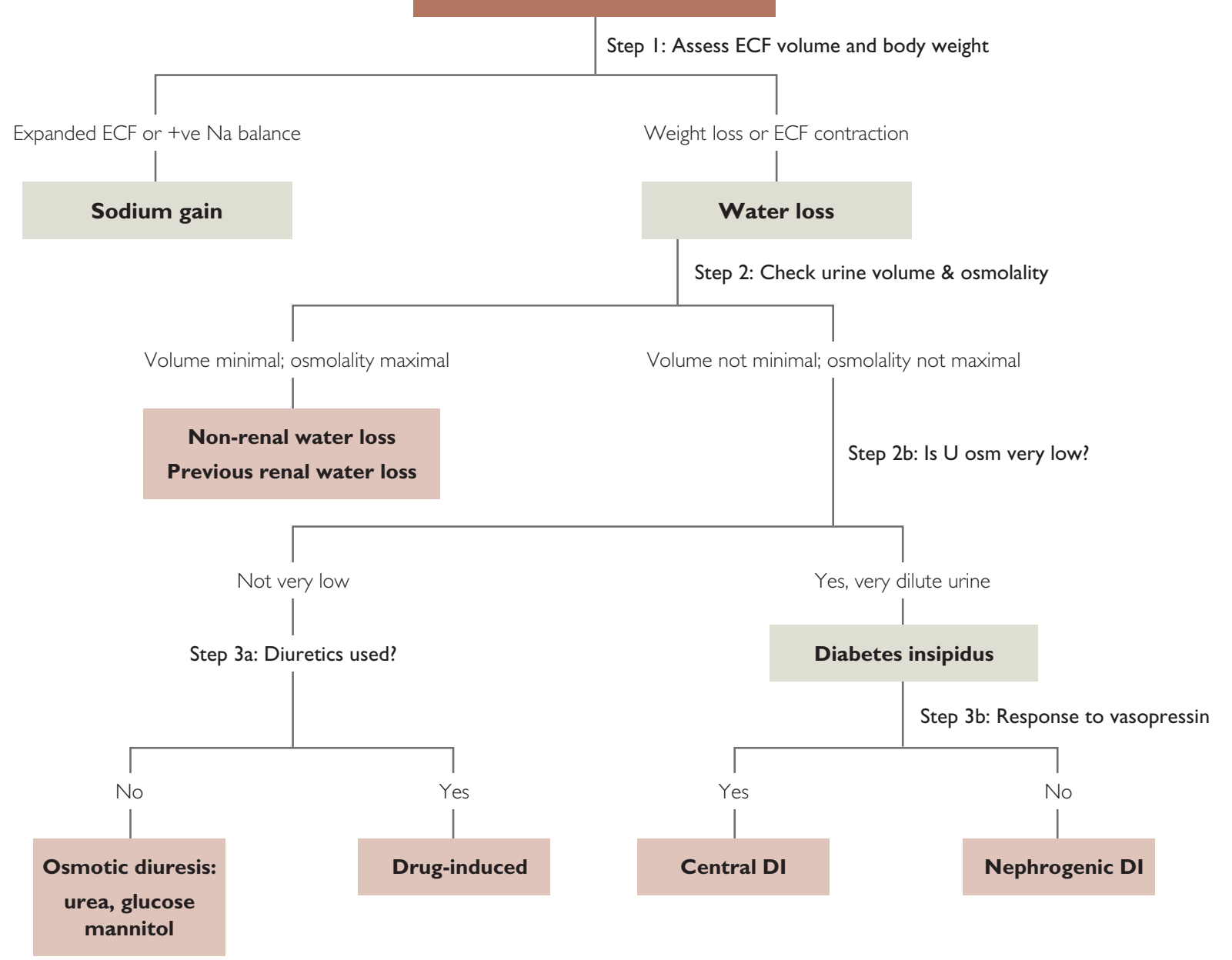

Figure I. A diagnostic approach to hypernatraemia.

In patients with hypernatraemia on admission to hospital, a large water deficit is usually the basis of the hypernatraemia, and replacement of water is the mainstay of treatment. However, when hypernatraemia develops during a hospital admission, sodium gain is often a major contributor to the condition, and the treatment therefore includes creating a negative balance for sodium. Acute hypernatraemia can be corrected rapidly; however, hypernatraemia that is chronic should be corrected at a rate no faster than $8 \mathrm{mmol} / \mathrm{L} /$ day to avoid cerebral oedema [I].

Hypernatraemia is a common clinical problem in hospitalized patients, with the prevalence ranging between $0.5 \%$ and $2 \%$. In critically ill patients treated in an intensive care unit (ICU), the prevalence ranges from 2-6\% on admission to the ICU. Several studies have reported an association between hypernatraemia and in-hospital mortality.

A Canadian study of 8142 critically ill adult patients identified ICU-acquired hypernatraemia in 26\% [4]. The mor- tality rate was $34 \%$, as compared to $16 \%$ in patients with normal sodium concentrations. In the United States, the overall prevalence of hospitalized patients with hypernatraemia ranges from $0.3-5.5 \%$. Most cases are hospitalacquired and the proportion of patients who have hypernatraemia on admission is estimated at 0.12-1.4\%. A considerably higher prevalence of $9-26 \%$ is seen in critically ill patients [5]. A single-centre study from Europe, which included 981 patients, found a $9 \%$ incidence of hypernatraemia in the ICU, with 23\% having hypernatraemia on admission to the ICU [6].

There are very few data on hypernatraemia in hospitalized patients from the developing world, and from Africa in particular. We identified only one African study, published in 1999, which reported on hypernatraemia at the Mthatha General Hospital in the Eastern Cape province of South Africa [7]. The study included 98 patients with hypernatraemia and reported a prevalence of $1.4 \%$ and an overall 
mortality of $56 \%$. Hospital-acquired hypernatraemia was more frequently observed than hypernatraemia on admission (59\% versus $41 \%)$.

The present study adds to the sparse data on hypernatraemia in African settings by reporting on the causes, management and outcomes of hypernatraemia in hospitalized patients at a large tertiary hospital in Cape Town, South Africa.

\section{METHODS}

A retrospective, descriptive study was conducted at Tygerberg Hospital (TBH), a 1380 -bed teaching hospital in Cape Town. $\mathrm{TBH}$ provides secondary and tertiary level care to approximately 1.5 million people in the Western Cape province. Laboratory services are provided by the National Health Laboratory Service (NHLS).

Adult patients with hypernatraemia $\left(\left[\mathrm{Na}^{+}\right] \geq 150 \mathrm{mmol} / \mathrm{L}\right)$ were identified from the NHLS database for a 3-month period (July-September 2014). Patient records were examined and a standardized data capture sheet used to extract information on demographics, clinical diagnosis, comorbidities, treatment and outcomes.

During the period of the study, serum sodium and other electrolyte concentrations were measured on a Siemens ADVIA 1800 Clinical Chemistry Analyzer, which uses an ion-selective electrode. At high sodium concentrations, the within-run coefficient of variation (CV) was $0.8 \%$ and the total CV was 1.1\%.

Descriptive analysis was reported as means \pm standard deviations and proportions. Chi-squared and Fisher's exact tests were used to compare proportions. Statistical significance was set at $p<0.05$.

Ethics approval for the study was granted by the Health Research Ethics Committee of Stellenbosch University (reference number S17/01/007).

\section{RESULTS}

There were 204 patients with hypernatraemia out of I 3342 total admissions during the study period, yielding a prevalence of $1.5 \%$. Of the hypernatraemic patients, 101 (49.5\%) were male. The mean age was $53 \pm 19$ years (range |8-9| years).

There were 66 patients (32.4\%) who had hypernatraemia on admission, and 138 who developed the condition during the course of their hospital stay. Of those admitted with hypernatraemia, there were 10 (15\%) whose hypernatraemia worsened after admission.

The patients were approximately evenly distributed between the medical (98 patients, 48\%) and surgical wards
(52\%) (Table I). The mean duration of their hospital stay was $15 \pm 16$ days and the median duration was 9 days (interquartile range 5-19 days).

There were 49 patients who were admitted to our medical and surgical ICUs, 9 of whom (18\%) were admitted with hypernatraemia whereas 40 patients (82\%) developed it during their stay in hospital. Of these 40 patients, 7 had a negative fluid balance and only 4 had water deficits sufficient to account for at least $50 \%$ of the rise in sodium concentration.

The most common contributory causes of hypernatraemia that were documented were dehydration/hypovolaemia (45\%) and sepsis (39\%) (Table 2).

Regarding complications or symptoms which could be related to hypernatraemia, 37 patients had confusion, 18 had seizures and 20 suffered loss of consciousness. Only 25 patients (33\%) had clearly documented neurological improvement after treatment (Table 3).

\begin{tabular}{|lcc|}
\hline \multicolumn{3}{|l|}{$\begin{array}{l}\text { Table I. Distribution of patients with hypernatraemia } \\
\text { by ward. }\end{array}$} \\
\hline Ward & $\mathrm{n}=204$ & Adm. \% \\
\hline Medical ward & $86(42 \%)$ & 42 \\
Medical ICU & $12(6 \%)$ & 17 \\
Surgical ward & $69(34 \%)$ & 30 \\
Surgical ICU & $37(18 \%)$ & 19 \\
\hline
\end{tabular}

"Adm. \%: Percentage of patients with hypernatraemia present on admission. Peak $\left[\mathrm{Na}^{+}\right]$ranged from $150-185 \mathrm{mmol} / \mathrm{L}$, with a mean of $155 \pm 6 \mathrm{mmol} / \mathrm{L}$. The mean peak $\left[\mathrm{Na}^{+}\right]$for patients who were admitted with hypernatraemia was $154 \pm 6$ vs. $155 \pm 5 \mathrm{mmol} / \mathrm{L}$ for those who developed hypernatraemia during the course of their hospital stay.

Table 2. Contributory causes of hypernatraemia.

\begin{tabular}{|lc|}
\hline Cause & $\mathrm{n} \%^{*}$ \\
\hline Dehydration/hypovolaemia & $92(45)$ \\
Renal failure & $79(39)$ \\
DM/DKA** & $55(27)$ \\
GIT & $54(26)$ \\
Diuretic use & $41(20)$ \\
Head injuries & $38(19)$ \\
Burns & $17(8)$ \\
Malignancy & $11(5)$ \\
Epilepsy & $8(4)$ \\
\hline
\end{tabular}

"More than half the patients had more than one contributory cause of hypernatraemia; these patients are counted more than once. ${ }^{* *}$ DM/DKA: uncontrolled diabetes, including diabetic ketoacidosis. 
Table 3. Complications of hypernatraemia.

\begin{tabular}{|lc|} 
Neurological manifestation & $\mathrm{n}^{*}$ \\
\hline Confusion & $37(18 \%)$ \\
Seizure & $18(9 \%)$ \\
Loss of consciousness & $20(10 \%)$ \\
\hline
\end{tabular}

"Patients may be counted more than once.

\begin{tabular}{|lccc|}
\hline \multicolumn{4}{l}{ Table 4. Distribution of serum sodium concentration and } \\
outcomes. \\
\hline$[\mathrm{Na}+](\mathrm{mmol} / \mathrm{L})$ & $\mathrm{n}$ & Died & Died \% \\
\hline $150-154$ & 137 & 40 & 29 \\
$155-159$ & 31 & 15 & 48 \\
$160-164$ & 20 & 15 & 75 \\
$\geq 165$ & 16 & 10 & 63 \\
\hline
\end{tabular}

There was little documentation regarding diagnostic workup, and only five of the 204 hypernatraemic patients had samples sent to the laboratory for measurement of urine sodium or osmolality.

Unfortunately, there was also poor documentation of the management of the hypernatraemia, especially in the general medical and surgical wards. The available records indicated that most of the patients received $0.9 \%$ saline, and 62 patients were prescribed tap water and/or 5\% dextrose water.

The overall mortality was $38.7 \%$, with a somewhat higher unadjusted mortality rate for those patients who had developed hypernatraemia during their hospital stay than for those admitted with hypernatraemia. This difference was not statistically significant (42\% vs. $31.8 \%, p=0.213$ ). There was also no difference in mortality between patients with documented neurological symptoms and those without (37\% vs. 49\%, $p=0.189$ ). The unadjusted mortality rate was lower in patients whose hypernatraemia resolved on treatment (29\% vs. $49 \%, p=0.004$ ) and highest for patients with sodium concentrations above $160 \mathrm{mmol} / \mathrm{L}$ (75\% mortality, Table 4).

On adjusted (multivariate) analysis, there was an independent association of death with age and the severity of the hypernatraemia (Table 6).

\section{DISCUSSION}

Our study revealed a prevalence of hypernatraemia of $1.5 \%$, a figure similar to the Mthatha study from the Eastern Cape [7]. One-third of our patients had neurological signs or symptoms, much higher than in previous studies [5].

Table 5. Comparison of patients admitted with hypernatraemia versus those who developed the condition during their hospital stay.

\begin{tabular}{|c|c|c|c|}
\hline & Hypernatraemia on admission & Hypernatraemia after admission & $\mathrm{P}$-value \\
\hline Number & $66(32.4 \%)$ & I $38(67.6 \%)$ & \\
\hline Age (years) & $53.6 \pm 20$ & $52.8 \pm 19$ & 0.966 \\
\hline Duration of hospital stay (days) & $6(2-11)$ & $13(6-2 \mid)$ & $<0.00$ । \\
\hline Hypernatraemia normalized & 35 (53\%) & $61(44 \%)$ & 0.291 \\
\hline Mortality & $31.8 \%$ & $42.0 \%$ & 0.213 \\
\hline Peak $\left[\mathrm{Na}^{+}\right]$ & $154.4 \pm 6.3$ & $154.8 \pm 5.3$ & 0.923 \\
\hline Neurological complications & $24(36 \%)$ & $42(30 \%)$ & 0.484 \\
\hline
\end{tabular}

Table 6. Multiple logistic regression analysis of baseline risk factors associated with in-hospital mortality in patients with hypernatraemia.

\begin{tabular}{|c|c|c|c|}
\hline Characteristic & Odds ratio & $(95 \% \mathrm{Cl})$ & $\mathrm{P}$-value \\
\hline Age & 1.02 & $1.00-1.03$ & 0.031 \\
\hline Peak $\mathrm{Na}^{+}$concentration & 1.11 & $1.05-1.18$ & $<0.00$ । \\
\hline Neurological symptoms & 0.63 & $0.29-1.37$ & 0.246 \\
\hline Admission hypernatraemia & 0.55 & $0.28-1.08$ & 0.085 \\
\hline
\end{tabular}


Our overall mortality rate was 38.7\%, considerably lower than the Mthatha study and other studies from the developed world $[5,7]$. The age of our patients was similar to the Mthatha study but lower than that reported in most developed-world studies; this would be expected to influence mortality rates [4].

The mortality rate was highest for older patients and those with higher sodium concentrations, as has been reported previously [5], and there was a higher mortality rate in those patients where serum sodium concentrations did not normalize with treatment. The most common factors that may have contributed to the hypernatraemia were dehydration/hypovolaemia, sepsis and renal failure. More than half the patients had more than one potential cause of hypernatraemia. These findings are similar to those of the Mthatha study.

Most of our patients were being managed in the general medical and surgical wards. Other studies have reported a greater proportion of hypernatraemic patients being managed in an ICU setting [4-6]. A possible reason for this is that there are relatively few beds in our medical and surgical ICUs, and critically ill patients are often managed in general wards when ICU beds are not available. It is also possible that there may be greater awareness of the significance of hypernatraemia and its management in our ICUs, where more care might be taken to prevent hypernatraemia by, for example, more frequent monitoring of electrolytes and appropriate adjustments of fluid prescription.

Most patients developed hypernatraemia during their stay in hospital. There was no difference in mortality rate between these patients and those who had hypernatraemia on admission.

To understand the mechanisms underlying the development of hypernatraemia, it is useful to perform a tonicity balance and consider the contributions of net water deficit and/or net sodium gain in each patient [8]. This should guide the therapy required and requires accurate charting of the intake and output for the period during which the hypernatraemia develops. At a minimum, the volumes of fluid taken in and excreted need to be known, even if the solute content of the fluids is not. If the negative fluid balance (net water loss) is not sufficient to explain the rise in $\left[\mathrm{Na}^{+}\right]$, then sodium gain can be inferred. Our study included $40 \mathrm{ICU}$ patients with good documentation of input and output. Of these, 33 had positive fluid balances, 3 had small negative fluid balances and only 4 had large negative fluid balances sufficient to explain at least $50 \%$ of the rise in $\mathrm{Na}^{+}$. Sodium gain was therefore the main mechanism in at least $90 \%$ of these ICU cases. Similar findings have been reported previously $[9,10]$.
An important finding from our study was the almost complete absence of clearly documented diagnostic work-ups for hypernatraemia. In addition, there was documented prescription of hypotonic fluid or tap water in less than half of the cases. This suggests a lack of appreciation of the importance of hypernatraemia and/or lack of knowledge regarding its diagnostic work-up and management.

Our study has several limitations. In particular, the available documentation was poor in many cases. This included incomplete information on fluid input and output volumes, as well as the type of fluid administered. The documentation was better in the ICUs than in the general wards.

\section{CONCLUSION}

Hypernatraemia has significant associated mortality and should be a priority for early recognition and treatment in hospitalized patients. The diagnostic work-up and management need to be improved with the aid of standardized protocols. Appropriate laboratory studies should include the measurement of urine electrolyte concentrations and osmolality. Good documentation of the diagnostic workup, fluid prescription, and input and output volumes is essential.

\section{REFERENCES}

I. Kamel KS, Halperin ML. Fluid, electrolyte, and acid-base physiology: a problem-based approach. 5th ed. Philadelphia, PA: Elsevier; 2017.

2. Sterns RH. Disorders of plasma sodium — causes, consequences, and correction. New Engl J Med. 20I5; 372:55-65.

3. Chassagne P, Druesne L, Capet C, Ménard JF, Bercoff E. Clinical presentation of hypernatremia in elderly patients: a case control study. J Am Geriatr Soc. 2006; 54:1225-1230.

4. Stelfox HT, Ahmed SB, Khandwala F, Zygun D, Shahpori R, Laupland $K$. The epidemiology of intensive care unit-acquired hyponatraemia and hypernatraemia in medical-surgical intensive care units. Crit Care. 2008; 12:RI62.

5. Darmon M, Timsit J-F, Francais A, Nguile-Makao M, Adrie C, Cohen $Y$, et al. Association between hypernatraemia acquired in the ICU and mortality: a cohort study. Nephrol Dialysis Transpl. 2010; 25:2510-2515.

6. Lindner G, Funk G-C, Schwarz C, Kneidinger N, Kaider A, Schneeweiss B, et al. Hypernatremia in the critically ill is an independent risk factor for mortality. Am J Kidney Dis. 2007; 50:952-957.

7. Erasmus R, Matsua T. Frequency, aetiology and outcome of hypernatraemia in hospitalised patients in Umtata, Transkei, South Africa. East Afr Med J. 1999; 76:85-88.

8. Davids MR, Edoute Y, Mallie JP, Bichet DG, Halperin ML. Body compartment volumes and composition after giving a vasopressin antagonist: changes are revealed by a tonicity balance. Nephrol Dial Transplant. 2002; 17:300-303.

9. Hoorn EJ, Betjes MG, Weigel J, Zietse R. Hypernatraemia in critically ill patients: too little water and too much salt. Nephrol Dial Transpl. 2007; 23:1562-1568.

I0. Lindner G, Kneidinger N, Holzinger U, Druml W, Schwarz C. Tonicity balance in patients with hypernatremia acquired in the intensive care unit. Am J Kidney Dis. 2009; 54:674-679. 